\title{
Regenerative Braking Experimental Tests and Results for Formula Student Car
}

\author{
Leone Martellucci, Marco Giannini \\ Department of Astronautical, Electrical and Energy Engineering, Sapienza University, Rome, Italy \\ Email: leone.martellucci@uniroma1.it,mk.giannini96@gmail.com
}

How to cite this paper: Martellucci, L. and Giannini, M. (2021) Regenerative Braking Experimental Tests and Results for Formula Student Car. Journal of Transportation Technologies, 11, 78-89. https://doi.org/10.4236/jtts.2021.111005

Received: November 30, 2020

Accepted: January 23, 2021

Published: January 26, 2021

Copyright $\odot 2021$ by author(s) and Scientific Research Publishing Inc. This work is licensed under the Creative Commons Attribution International License (CC BY 4.0).

http://creativecommons.org/licenses/by/4.0/

\section{(c) (i) Open Access}

\begin{abstract}
In this paper, the tuning process of a regenerative braking system for a full electric Formula Student car is reported. Experimental results will be discussed and recovered energy will be measured. In order to obtain the best tuning some preliminary requirements have been decided: no-slip motion of traction wheels during braking phase, no over current and over voltage of Li-ion cells and the best feeling from the braking pedal for the driver. The main target of the regenerative braking system is to obtain the maximum recovered energy during the Endurance event in a typical Formula Student Competition (FS Germany, Hockenheim ring). First, an accurate estimation of the admissible braking torques with the tires used was carried out, starting from the magic formula of Pacejka of the tires. The maximum electric braking torque that the installed engine can provide at various speeds was then estimated, compatibly with the charging currents allowed by the storage system. Subsequently, a mechanical regulating device for regenerative braking was designed and described here, installed directly on the gear lever system that connects the brake pedal to the brake pumps. The proposed system is able to appropriately delay the entry into action of the hydraulic brake pumps and this delay is mechanically adjustable by acting on threaded pins. In this way, the interval of actuation of the brake pedal which activates only the electric braking can be adjusted and tuned. Finally, the overall project was tested on the track, in order to validate the hypotheses previously calculated and determine the setting capable of optimizing the energy recovered during a test equivalent to the Endurance event, compatibly with the constraints of the installed systems on board.
\end{abstract}

\section{Keywords}

Vehicle, Electric, Braking, Regenerative, Experimental 


\section{The Case Study}

The car covered by this paper responds entirely to the dictates of the Formula Student rules, both as SAE (society of automotive engineers) and FSG (Formula student Germany). Formula student is an international championship where university students test themselves designing and building three different categories of single seater race car: Electric, internal combustion and autonomousdriving cars. The rules give the main guide-lines to fulfill in order to guarantee, overall, safety of driver and stewards. Formula student's competitions are constituted by statics engineering events and track tests. The track tests give the main part of all competition's points and the most important is the endurance test: a race of $22 \mathrm{~km}$ in a very technical track characterized by frequent acceleration and braking.

The car considered in this paper (Figure 1) is from "Sapienza Fast Charge" team and present the following characteristics. The rolling chassis is a steel tube space frame structure with A-arms and push rod suspensions; hubs and uprights in ergal aluminum alloy, with magnesium alloy wheel with Pirelli slick tires. The complete vehicle weighs, without the driver on board, $240 \mathrm{~kg}$, the battery pack alone weighs $54 \mathrm{~kg}$, and the motor and inverter weigh $20 \mathrm{~kg}$. The overall weight distribution is $50: 50$ considering a $75 \mathrm{~kg}$ driver and the aerodynamic kit that is composed by front wing, rear wing and undertray with diffuser. The car is equipped with $6.3 \mathrm{kWh}$ energy storage (Figure 2) in 90s3p configuration using li-po pouch cells, with $380 \mathrm{~V}$ of maximum voltage and capable of $150 \mathrm{~A}$ of burst charge current, to be considered in the regenerative braking system design. Energy storage's container is built by carbon and kevlar fiber in order to enhance the power-to-weight ratio and guarantee excellent electric-insulation, flame resistance and mechanical proprieties.

Electronics and safety systems are partially commercial and partially from Team's design: The Vehicle Control Unit, specific for automotive applications, is programmable with MATLAB-Simulink and the Battery Management System (BMS) is commercial but with firmware modified by the team. The BMS allows monitoring and logging temperatures and voltage of each cell parallel, in order to collect large amount of experimental data; it is useful in particular for regenerative braking, because burst charge during regenerative braking is thermally stressful for the li-po cells. The full electric powertrain is made up by a permanent magnet axial flux motor that delivers $100 \mathrm{~kW}$ and $240 \mathrm{Nm}$; it is connected to the wheels with a chain transmission with $11 / 45$ pinion/crown ratio and an adjustable Limited Slip Differential. The electric drive is managed by a $450 \mathrm{~V}$ electronic inverter with canbus line communication with Vehicle Control Unit and data logging system. As already explained, main target of this case study is to set the best configuration of the regenerative braking device in order to maximize the total recovered energy during braking phase (without rear wheels locking) in a typical Formula Student Endurance Event. As result of this work, the expected recovered energy during the Endurance Event will be evaluated 

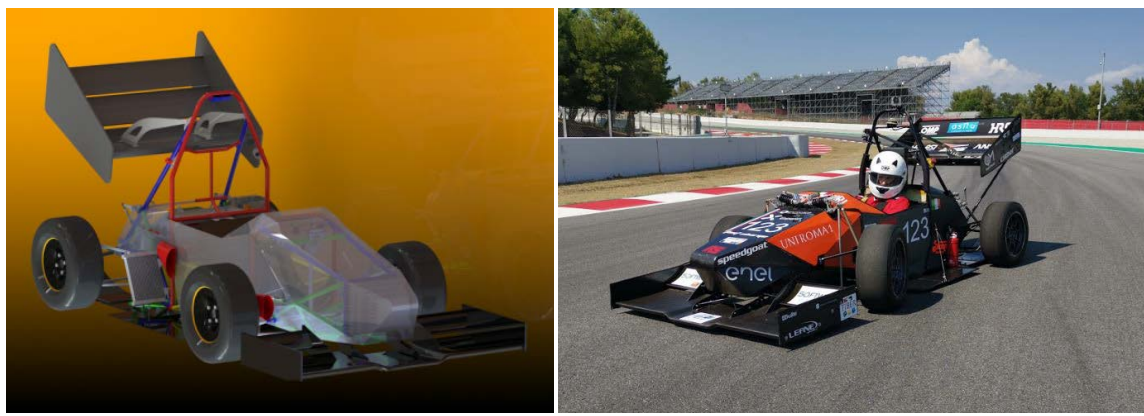

Figure 1. The Formula Student car (courtesy by Sapienza Fast Charge Team).
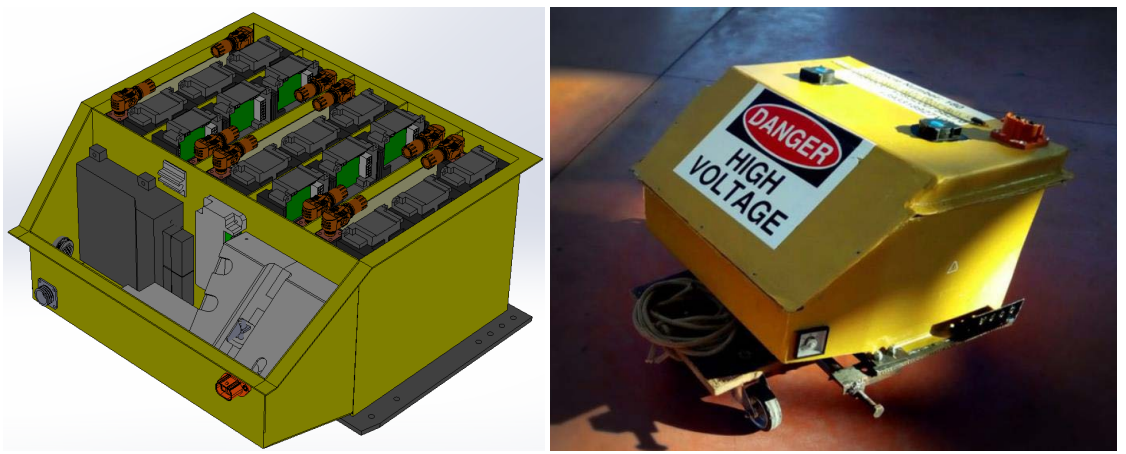

Figure 2. The storage system (courtesy by Sapienza Fast Charge Team).

considering all the system constrains [1]; it will be very important information in order to design the new storage system for Season 2021 car. In order to develop the project of a Formula Student energy storage system, information is needed but the most important one is the energy required to complete endurance event. It is needed to choose the right configuration of cells in series and parallel to comply with battery pack voltage (nominal and maximum) in the best matching possible with inverter voltage range.

\section{The Regenerative Braking Process}

During a significant braking, typical of a Formula Student races, the load distribution on the two axles (front and rear) changes according to many parameters related to the kinematics and dynamics of the suspension system. The pitching movement of the chassis, a function of many parameters (ant dive, shock absorbers, barycentric axis, etc.), produces a shift of the vehicle weight towards the front wheels and a corresponding lightening of the rear wheels. The powertrain configuration of the Formula Student car described here is therefore not ideal for collecting energy from braking, as the braking torque that can be applied to the rear wheels is much lower than that which could be applied to the front wheels. It is precisely for this reason that an accurate optimization process of the entire regenerative braking phase is necessary [2] [3] [4]. In order to carry out a first simple study of the braking process some simplifications to the dynamic model of the vehicle have been introduced:

- If the applied braking torque is uniform, with brake forces constant during 
braking, the pitching movements are limited to the first phase of this time. During the rest of braking the vehicle maintains the pitch angle and then the suspensions have important role only in the short initial transient time. It is possible to consider the car as a unique rigid body.

- Aerodynamics forces in braking time can be ignored because considerably smaller then braking forces considering that hydraulic braking forces are in the order of magnitude of $10,000 \mathrm{~N}$ (calculated by the oil pressure in the brake line and the area of brake pads and pump) and that the aerodynamic drag is less than $800 \mathrm{~N}$.

- The rolling resistance is marginal because generally quantifiable in $1.5 \%$ of car weight.

Thus, considering:

- $W$ as weight force (applied to barycenter $\mathrm{G}$ ).

- $Z_{1}$ and $X_{1}$ as the vertical and horizontal reaction on the ground of front tires.

- $Z_{2}$ and $X_{2}$ as the vertical and horizontal reaction on the ground of rear tires.

- $u$ as vehicle speed.

- $I$ as wheelbase, $r$ the tire rolling radius $(0.26 \mathrm{~m})$ and $h$ the barycenter height. the following equation of vertical and horizontal axel dynamic equilibrium can be written:

$$
m \cdot \mathrm{d} u \cdot \mathrm{d} t=-\left(X_{1}+X_{2}\right), \quad W=Z_{1}+Z_{2}
$$

Considering $m$ as mass of vehicle with driver that worth $320 \mathrm{~kg}$ then, with 50:50 weight balance, the static weight distribution on front an rear axis $W_{1}$ and $W_{2}$ are:

$$
W_{1}=W_{2}=1570 \mathrm{~N}
$$

The constant pitch angle of the car during braking corresponds to a balancing of moments of forces considering the center of rotation in the contact point of the front tire with the ground:

$$
Z_{1}=W_{1}-m \cdot h l \cdot \mathrm{d} u \mathrm{~d} t, \quad Z_{2}=W_{2}-m \cdot h l \cdot \mathrm{d} u \mathrm{~d} t
$$

The brake forces can be estimate considering friction coefficient between tire and ground (with Avon slick Formula Student tires it worth 1.3):

$$
X_{1}=Z_{1} \cdot \mu, \quad X_{2}=Z_{2} \cdot \mu
$$

If the car reaches a deceleration of $1 \mathrm{~g}$ (maximum theoretical deceleration, obtained by ADAMS Car simulation with optimal condition of ground and tires),

$$
\mathrm{d} u \mathrm{~d} t=-9.81 \mathrm{~m} / \mathrm{s}^{2}, \quad l=1.640 \mathrm{~m}, \quad h=0.339 \mathrm{~m}
$$

braking forces on rear and front axles are:

$$
X_{1}=2218 \mathrm{~N}, \quad X_{2}=920 \mathrm{~N} \text {, }
$$

Then, it is possible to calculates the value of the braking torque on front and rear wheels (two wheels torque summed):

$$
T_{a}=X_{1} \cdot r=750 \mathrm{~N} \cdot \mathrm{m}, \quad T_{r}=X_{2} \cdot r=311 \mathrm{~N} \cdot \mathrm{m}
$$


Thus, the value of the torque that can be requested to the inverter for the motor for regenerative braking phase cannot be higher than:

$$
C=T_{r} \cdot \frac{\omega_{w}}{\omega_{m}}
$$

where $C$ is the torque supplied by the motor, $\omega_{m}$ is the angular speed of the motor, $\omega_{r}$ is the angular speed of the wheels. Considering that $\omega_{m}=\omega_{r} \cdot 4.09$ where 4.09 is the transmission ratio, we get that the motor torque $C$ could be at maximum $C=76 \mathrm{Nm}$, to avoid rear wheels lock [5]. This value is useful to configure the inverter and VCU to obtain the maximum theoretical braking torque (to be verified on track). This braking torque produces a power flow to the battery pack that depends on the vehicle speed. Now, it is important to verify that maximum regenerative power does not exceed the maximum charging power and current of Li-ion cells. Considering a regenerative braking phase starting with vehicle running at $27.7 \mathrm{~m} / \mathrm{s}$, the maximum regenerative power with $76 \mathrm{Nm}$ of braking torque deployed by motor can be calculated starting from the mechanical power $P=\omega \cdot C$, where $P$ is the power, $C$ is the torque calculated and $\omega$ motor angular speed. Assuming $u=27.7 \mathrm{~m} / \mathrm{s}$ as vehicle speed, $r=0.265 \mathrm{~m}$ as rolling radius and the transmission ratio of 4.09 , the angular speed of the motor is $418 \mathrm{rad} / \mathrm{s}$, thus, the maximum regenerative power is:

$$
P=\omega \cdot C=31806 \mathrm{~W}=31.8 \mathrm{~kW}
$$

Assuming $V_{i n V}$ the inverter DC link voltage, $I$ the DC current, $V_{o c v}$ the open circuit voltage of accumulator, $R_{p}$ the total impedance of accumulator (in $3 \mathrm{p} 90 \mathrm{~s}$ configuration) and $R_{c}=1.2 \mathrm{~m} \Omega$ the single cell impedance.

$$
R_{p}=90 \cdot \frac{1}{\left(\frac{3}{R_{c}}\right)}=36 \mathrm{~m} \cdot \Omega,\left\{\begin{array}{l}
P=V_{i n v} \cdot I \\
V_{o c v}=R_{p} \cdot I+V_{i n v}
\end{array}\right.
$$

and, with some simplifications:

$$
I^{2} R_{p}-V_{\text {ocv }} \cdot I+P=0
$$

Assuming for $V_{o c v}$ the minimum battery pack overall voltage, equal to $270 \mathrm{~V}$, to be conservative, the maximum admissible regenerative current is $120 \mathrm{~A}$. The pouch Li-ion cells utilized in the battery pack can accept $8 \mathrm{C}$ of maximum burst charge current, thus, considering that we have three cells connected in parallel and each cell have a capacity of $6.3 \mathrm{Ah}, 151.2 \mathrm{~A}$ is the regenerative current limit, higher than the current calculated at the tires grip limit [6].

\section{The Regenerative Braking Device}

The single seater car is equipped with two separate hydraulic circuits, each operated by its own pump, which control the mechanical braking on the front and rear axles, in accordance with the regulations. The pumps used are AP Racing CP6465 with a piston stroke of $25.4 \mathrm{~mm}$. They are pull type pumps and the 
compact design is particularly suitable for motorsport applications.

The energy disadvantage to regenerative braking due to the positioning of the electric motor on the rear wheels requires the adoption of techniques to optimize the intervention of the electric braking. In particular, it is important to avoid that the simultaneous hydraulic braking dissipates energy during electric braking [7] [8] [9]. A device has therefore been designed (Figure 3) which can inhibit the actuation of the brake pumps during the first part of the brake pedal stroke; the device allows a first pedal stroke useful only for regenerative braking, and a second part in which the brake pumps are truly operated by the pedal. The device is equipped with an adjustment to modify the amplitude of the "idle" stroke to adapt it to the driver's driving style and to the track characteristics. In Figure 3 the device, called regenerative braking regulator, is represented. A fundamental element of the device is the possibility of varying the braking force of the hydraulic circuits to the full advantage of regenerative braking. This can be done through the setting cylinders that connect the pistons of the pumping elements to the brake pedal. With the interposition of the setting cylinders, the brake pedal is not directly connected to the pumping elements, so there is a part of the stroke of the brake pedal that does not correspond to the mechanical actuation of the pumping elements. Precisely in this first part of the adjustable braking, the braking can be implemented electronically (thanks to a rotary potentiometer on brake pedal) and therefore be implemented exclusively with regenerative braking. Furthermore, it is possible to set the front and rear brake pumps independently, and this is very important in consideration of the regenerative braking exclusively at the rear. Therefore, the type of braking developed by the team involves mechanical braking at the front and a combination of mechanical and electrical braking at the rear. The aim of this work is to find the optimal setting between the two types of braking on the rear axle of the vehicle.
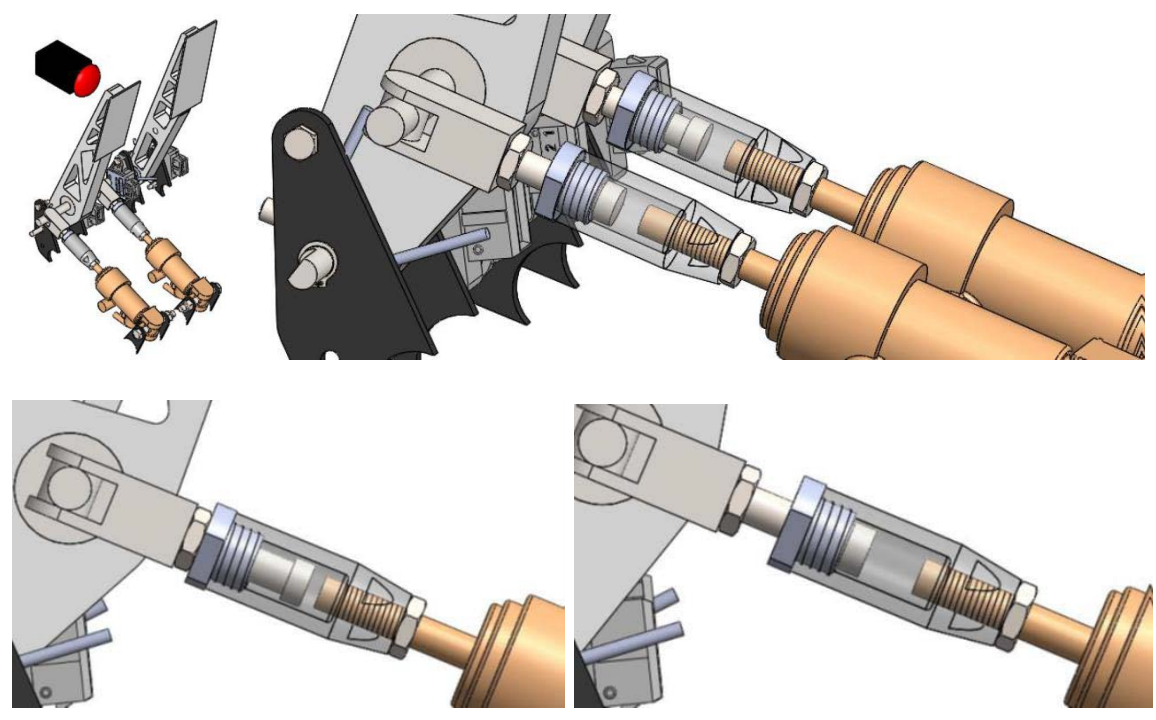

Figure 3. Regerative braking regulator; assembly and examples of regulation of pedal stroke. 


\section{Track Tests}

The braking phase for a racing vehicle is of considerable importance for obtaining high performance in the lap time and for the safety and dynamics of the vehicle, especially aimed at vehicle driveability. In case of a fully electric racing vehicle, these traditional requirements are also supplemented, as mentioned, by maximizing the energy recovered during braking, which can provide a contribution of even $10 \%-15 \%$ to the range. This, in Formula Student, can make the difference between completing the endurance event or not and has a direct impact on the score of the efficiency event.

The braking phase is therefore particularly complex to analyze and necessarily requires an accurate experimental setup, in consideration of the numerous phenomena that influence its operation. A complete test campaign was then carried out aimed at defining the best setting point for the cylinders of the regenerative braking regulator, measuring the recovered energy, the dynamic behavior of the vehicle and its driveability. The tests were carried out on closed track at POMOS (Sustainable Mobility Center of Sapienza University) by reproducing the typical braking extrapolated from the acquisition of an endurance event at Formula Student Germany on the Hockenheim ring, shown in Figure 4. The braking tests are guided by colored cones at track side to indicate to the driver the start braking point and end braking point and are carried out by braking from a vehicle speed of $70 \mathrm{~km} / \mathrm{h}$ to $20 \mathrm{~km} / \mathrm{h}$, which represents the most frequent braking that occurs at an endurance event. As mentioned, the regulator device of the regenerative braking allows to modify the stroke part of the pedal dedicated to the regenerative braking only, being also able to set the front and rear braking differently; in addition, the inverter allows to adjust the maximum current and maximum braking torque. therefore, a set of configurations was defined and tested on the track.

The car under test is equipped with an on-board data logging system connected to numerous analog sensors; the data logger is also inserted in the can bus network of the car to which the inverter and the battery management system are also connected. In particular, for the regenerative braking tests, the two brake fluid pressure sensors in the system (front and rear circuits), the brake pedal potentiometer and the pick-up inductive sensors mounted on the four wheels are particularly useful. In addition to these analog measurements, the information relating to the input or output current to the battery pack, its voltage, the rotational speed of the electric motor and its driving or braking torque are measured through the vehicle can bus network. For further integration, a GPS signal is available to be crossed with the measurements of the rotation speeds to measure the actual speed of the car net of wheel slip. As regards the management of braking by the inverter, it is possible to use the "Brake Linear Current" (BLC from now) parameter to define the maximum allowed braking current. The unit of measurement is expressed in 1/1000 of the rated stator current of the synchronous motor, for EMRAX 228 equal to 160 Arms. In this way, the maximum electric braking torque at the rear is decided; the regenerative couple, in fact, corresponds to: 


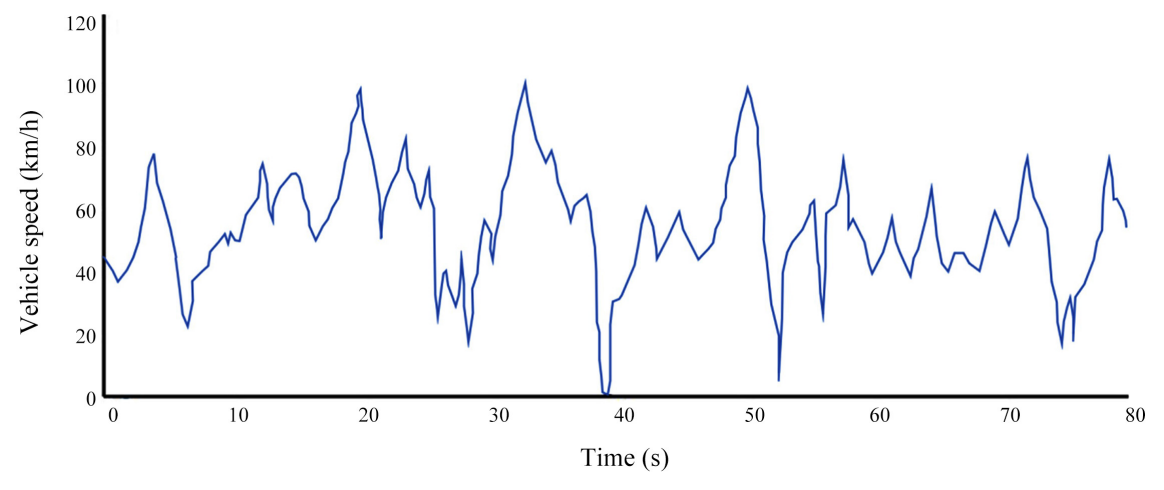

Figure 4. Speed vs time graph of a lap at Formula Student Germany.

$$
T_{m}=B L C \cdot K_{t} \cdot \frac{I_{r m s n}}{1000}
$$

where $T_{m}$ is the synchronous motor torque, $K_{t}$ motor torque constant and $I_{r m s n}$ the root mean square value of the rated current of a stator phase. Five values of the $B L C$ parameter have been selected, 350, 400, 425, 450 and 650, which correspond respectively to the maximum braking torques $32 \mathrm{Nm}, 48 \mathrm{Nm}, 51 \mathrm{Nm}$, $54 \mathrm{Nm}$ and $78 \mathrm{Nm}$. During the tests, for each maximum regenerative torque, the setting cylinder of the front hydraulic circuit has been set in three different positions. The rear brake system setting cylinder has always been left unscrewed, to maximize the portion of braking related to regeneration. In this way, a total of fifteen different configurations were tested and compared. The various tests will be marked with the initials YX0 - 0 - Z; the first three digits relate to the maximum regenerative braking current parameter $B L C$, the central 0 relates to the position of complete unscrewing of the rear system setting cylinder, the last digit relates to the tightening turns of the front setting cylinder. The following configurations of the braking regulator cylinders were therefore tested during the tests:

- YX0 - 0 - 0, both setting cylinders are completely unscrewed, this allows exclusively regenerative braking up to $70 \%$ of the travel of the brake pedal.

- YX0 - 0 - 3, rear setting cylinder completely unscrewed, front setting cylinder screwed by 3 turns, this allows exclusively regenerative braking up to $50 \%$ of the brake pedal travel.

- YX0 - 0 - 6, rear setting cylinder completely unscrewed, front setting cylinder screwed by 6 turns, this allows exclusively regenerative braking up to $30 \%$ of the brake pedal travel.

To calculate the energy regenerated during braking, the current entering the pack and the total voltage of the battery pack are used, which determine the regenerated power. Net of the losses due to the joule effect generated by the resistance of the elements that make up the internal circuit of the battery pack, the energy is then obtained by integrating the net power transferred to the batteries into the braking time. Table 1 shows the summary of the tests carried out, with the main parameters that govern the braking and regeneration processes. Each 
Table 1. Main results of $70 \mathrm{~km} / \mathrm{h}-30 \mathrm{~km} / \mathrm{h}$ braking tests.

\begin{tabular}{lccccc}
\hline $\begin{array}{c}\text { Braking } \\
\text { Settings }\end{array}$ & $\begin{array}{c}\text { Recovered } \\
\text { Energy } \\
(\boldsymbol{W h})\end{array}$ & $\begin{array}{c}\text { Braking } \\
\text { Duration } \\
(\boldsymbol{s})\end{array}$ & $\begin{array}{c}\text { Max regen } \\
\text { current } \\
(\boldsymbol{A})\end{array}$ & $\begin{array}{c}\text { Max } \\
\text { Deceleration } \\
(\boldsymbol{g})\end{array}$ & $\begin{array}{c}\text { Driveability } \\
\text { problems }\end{array}$ \\
\hline $\mathbf{6 5 0 - 0 - 0}$ & 6.25 & 4.65 & 69 & 0.9 & Yes \\
$\mathbf{6 5 0 - 0 - 3}$ & 10.48 & 4.20 & 69 & 1.1 & Yes \\
$\mathbf{6 5 0 - 0 - 6}$ & 5.79 & 4.62 & 56 & 1.3 & Yes \\
$\mathbf{4 5 0 - 0 - 0}$ & 6.26 & 3.70 & 50 & 1.1 & No \\
$\mathbf{4 5 0 - 0 - 3}$ & 4.75 & 4.40 & 48 & 1.4 & Yes \\
$\mathbf{4 5 0 - 0 - 6}$ & 7.45 & 3.41 & 51 & 1.2 & No \\
$\mathbf{4 2 5 - 0 - 0}$ & 3.85 & 2.64 & 45 & 1.4 & No \\
$\mathbf{4 2 5 - 0 - 3}$ & 2.17 & 2.19 & 30 & 1.9 & No \\
$\mathbf{4 2 5 - 0 - 6}$ & 2.44 & 3.42 & 35 & 1.7 & No \\
$\mathbf{4 0 0 - 0 - 0}$ & 4.30 & 3.90 & 45 & 1.2 & Yes \\
$\mathbf{4 0 0 - 0 - 3}$ & 5.10 & 2.44 & 44 & 1.3 & No \\
$\mathbf{4 0 0 - 0 - 6}$ & 5.69 & 2.82 & 43 & 1.4 & No \\
$\mathbf{3 5 0 - 0 - 0}$ & 5.30 & 3.75 & 43 & 1.2 & Yes \\
$\mathbf{3 5 0 - 0 - 3}$ & 5.45 & 2.69 & 40 & 1.3 & No \\
$\mathbf{3 5 0 - 0 - 6}$ & 6.55 & 3.60 & 40 & 1.2 & No \\
\hline
\end{tabular}

analyzed set was tested 10 times and the data reported here are the mean values measured. The tests are classified primarily according to the stability and safety of the car dynamic behavior, therefore the sets that have given driveability problems cannot be implemented safely, even in consideration of the unprofessional level of the Formula Student drivers. For example, in all the tests with parameter $B L C=650$ and therefore with $78 \mathrm{Nm}$ of maximum regenerative braking torque, the rear end arrives to the complete lock of the wheels with the formation of significant yaw motions until the car spun, due to the high regenerative torque at the rear. The best configuration of the regenerative braking system is therefore the 450-0-6, which highlighted a dynamic behavior of the car that is balanced and easily manageable, while ensuring a good value of recovered energy ( 7.45 Wh), a high maximum deceleration (1.2 $\mathrm{g}$ ) and a short braking time (3.41 s).

It is interesting to report an example of braking for the 450-0-6 configuration, to highlight the trends of the most relevant parameters among those measured during the test. In Figure 5, from top to bottom, shows respectively the position of the brake pedal (Brake Pedal), the longitudinal acceleration (ACC X), the recovered current (Ibattery), the pressure in the front brake circuit (Brake Front), the lateral acceleration (ACC Y) and the position of the accelerator pedal (Accelerator Pedal). From the energy point of view, a satisfying recovery current, with current values between $50 \mathrm{~A}$ and $20 \mathrm{~A}$ during the braking (3.4 s), is noted; the total energy recovered amounts to $7.4 \mathrm{Wh}$ and the generated currents are widely compatible with the data declared for the Li-ion cells. Braking is dynamically 
controllable and two short releases of the brake pedal by the driver can be seen in the graph of the pressure of the front brake hydraulic circuit (Brake Front) to manage the incipient locking of the front wheels. The low values of lateral acceleration data (ACC Y) highlights the stability of the vehicle dynamics under braking, with the absence of relevant lateral forces, while the longitudinal acceleration data (ACC X) reaches peaks of $1.2 \mathrm{~g}$ with regularity and a good intensity of the braking action.

The average data collected during the tests with the 450-0-6 configuration and the availability of the Fast Charge car speed data during a typical Endurace event (see Figure 4) allow a preliminary estimation of the amount of energy that can be recovered during the $22 \mathrm{~km}$ of a typical Formula Student Endurance event; Table 2 shows the six significant braking actions from an energy point of view that occur in an Endurance lap.

As mentioned, the tests carried out on the configurations of the braking recovery system take place between $70 \mathrm{~km} / \mathrm{h}$ and $30 \mathrm{~km} / \mathrm{h}$, therefore they are representative of the typical slowdown braking that precedes the most important corners in an Endurance. The layout of the track of Endurance in Formula Student events is based on Formula Student rules, therefore, the tracks have very similar features between the various international events. Table 3 shows the statistical evaluations of the total recovered energy which, as a first approximation, are obtained with the configurations of the regenerative braking system in Table 1 , limiting the analysis to only the configurations acceptable from the point of view of vehicle stability under braking.

The battery pack installed on board, as previously mentioned, has a stored energy of $6.30 \mathrm{kWh}$ and a total weight of $54 \mathrm{~kg}$; Table 3 shows the percentages of energy recovered during braking with respect to the total energy of the pack. The 450-0-6 configuration, the best in terms of both energy and vehicle dynamics, reaches a total of $890 \mathrm{Wh}$ of recovered energy, equal to $14.2 \%$ of the total. This value represents a vital margin to allow the battery pack used to properly power the propulsion system until the end of the Endurance event.



Figure 5. Recovered current during a braking in 450-0-6 configuration. 
Table 2. Significant braking in a lap of Fast Charge car at Endurance event (FSG).

\begin{tabular}{ccc}
\hline Braking & Initial Vehicle speed $[\mathrm{km} / \mathrm{h}]$ & Final vehicle speed $[\mathrm{km} / \mathrm{h}]$ \\
\hline 1 & 65 & 38 \\
2 & 75 & 40 \\
3 & 63 & 29 \\
4 & 55 & 34 \\
5 & 65 & 39 \\
6 & 76 & 35 \\
\hline
\end{tabular}

Table 3. Overall recovered energy in a typical Endurance event (FSG).

\begin{tabular}{ccc}
\hline Configuration & Recovered Energy (Wh) & \% of stored energy \\
\hline $\mathbf{4 5 0 - 0 - 0}$ & 750 & $11.8 \%$ \\
$\mathbf{4 5 0 - 0 - 6}$ & 890 & $14.2 \%$ \\
$\mathbf{4 2 5 - 0 - 0}$ & 460 & $7.3 \%$ \\
$\mathbf{4 2 5 - 0 - 3}$ & 260 & $4.1 \%$ \\
$\mathbf{4 2 5 - 0 - 6}$ & 290 & $4.7 \%$ \\
$\mathbf{4 0 0 - 0 - 3}$ & 610 & $9.7 \%$ \\
$\mathbf{4 0 0 - 0 - 6}$ & 680 & $10.8 \%$ \\
$\mathbf{3 5 0 - 0 - 3}$ & 650 & $10.4 \%$ \\
$\mathbf{3 5 0 - 0 - 6}$ & 780 & $12.5 \%$ \\
\hline
\end{tabular}

\section{Conclusion}

The study proposed here is aimed at the experimental analysis of the performance of an energy recovery braking system for Formula Student cars. In consideration of the mechanical and electrical characteristics of the car understudy and proposing a system for modulating the distribution between hydraulic and electric braking, the results of an experimental test campaign were presented and commented. The work carried out made it possible to define the optimal configuration for the brake pedal device and for the inverter; the value of energy recovered from braking during a typical Endurance event in Formula Student was then determined. The final results are consistent with the scientific literature on the subject and allow the definition of the car management strategies for the 2021 season.

\section{Acknowledgements}

Thanks to POMOS, Center for Sustainable Mobility of Sapienza University of Rome, for the infrastructures and laboratories made available for the implementation of the experimental activity.

Thanks to Andrea Milan and Marco Michelazzo for their support in the construction and experimental phases. 


\section{Conflicts of Interest}

The authors declare no conflicts of interest regarding the publication of this paper.

\section{References}

[1] Sovran, G. and Blaser, D. (2006) Quantifying the Potential Impacts of Regenerative Braking on a Vehicle's Tractive-Fuel Consumption for the U.S., European, and Japanese Driving Schedules. Technical Paper, SAE International, Warrendale. https://doi.org/10.4271/2006-01-0664

[2] Nian, X.H., Peng, F. and Zhang, H. (2014) Regenerative Braking System of Electric Vehicle Driven by Brushless DC Motor. IEEE Transactions on Industrial Electronics, 61, 5798-5808. https://doi.org/10.1109/TIE.2014.2300059

[3] Farshid, N., Ebrahim, F. and Teymoor, G. (2017) An Efficient Regenerative Braking System Based on Battery/Supercapacitor for Electric, Hybrid, and Plug-In Hybrid Electric Vehicles With BLDC Motor. IEEE Transactions on Vehicular Technology, 66, 3724-3738. https://doi.org/10.1109/TVT.2016.2611655

[4] Qiu, C.Q., Wang, G.L., Meng, M.Y. and Shen, Y.J. (2018) A Novel Control Strategy of Regenerative Braking System for Electric Vehicles under Safety Critical Driving Situations. Energy, 149, 329-340. https://doi.org/10.1016/j.energy.2018.02.046

[5] Pugi, L., Pagliai, M., Nocentini, A., Lutzemberger, G. and Pretto, A. (2017) Design of A Hydraulic Servo-Actuation Fed by A Regenerative Braking System. Applied Energy, 187, 96-115. https://doi.org/10.1016/j.apenergy.2016.11.047

[6] Wei, Y., Lin, Y. and Lin, C. (2005) The Study on Charge-Discharge Characteristics and Application of Li-Ion Battery for Vehicle. Vehicle Powertrain Technology, 2, 28-31.

[7] Yoong, M.K., Gan, Y.H., Gan, G.D., Leong, C.K., Phuan, Z.Y., Cheah, B.K. and Chew, K.W. (2010) Studies of Regenerative Braking in Electric Vehicle. IEEE Conference on Sustainable Utilization and Development in Engineering and Technolo$g y$, 20-21 November 2010, Petaling Jaya. https://doi.org/10.1109/STUDENT.2010.5686984

[8] Zhang, J.Z., Lv, C., Gou, J.F. and Kong, D.C. (2018) Cooperative Control of Regenerative Braking and Hydraulic Braking of An Electrified Passenger Car. Journal of Automobile Engineering, 226, 1289-1302. https://doi.org/10.1109/STUDENT.2010.5686984

[9] Aoki, Y., Suzuki, K. and Nakano, H. (2007) Development of Hydraulic Servo Brake System for Cooperative Control with Regenerative Brake. Technical Paper, SAE International, Warrendale. https://doi.org/10.4271/2007-01-0868 